\title{
COVID-19 - Digital Transformation and Digital Competency
}

\author{
P Venkat Kamesh \\ Fintech Professional \\ Coventry University
}

\begin{abstract}
The COVID-19 pandemic has caused serious and long-term disturbances in people's lives all over the world, in both developing and developed countries. This has led to financial crisis and great depression in the GDPs of many countries. It has not only impacted the Multi-National Businesses (MNCs) but also disturbed the Small and Medium Enterprises (SMEs) and life's of man vulnerable people.
\end{abstract}

As the crisis continues, the pandemic's pervasive impacts, which have affected every part of our communities, continue to unfold, leaving profound marks on people's livelihoods and countries' economies that are likely to persist for several years after the pandemic has ended.

As part of the global response to COVID-19, the digital technology industry especially Fintech (Financial Technology) has been instrumental in creating and delivering services and technologies that have mitigated, at least in part, the pandemic's effect on multiple aspects of people's lives in every part of the world. The Fintech companies and Start-ups have played a tremendous role in mitigating the inconvenience for the common people by implementing the next generation solutions for everyone and the people were quick to adopt to such a change.

The interest and surge of usage of Fintech applications (Digital applications related to Finance/ Payments/ Banking/ Ecommerce) carries in preserving people's livelihoods and businesses that have been, and continue to be, threatened by the pandemic COVID-19.

This working paper will discuss about the impact of digital payments in the developing country like India during COVID19, Pre-COVID-19, evolution of digital transformation in India from the past few years, People adoption to digital technologies, digital literacy intensification in emerging markets and also discusses the future trends of Fintech and its impact on consumers and businesses even after the pandemic ends.

Keywords: FinTech, COVID-19, Economy, Banking, Digital Payments, Digitalization

Objectives

- To Provide overview of evolution of Digital technology with more focus on Fintech in India in the last couple of years.

- How Fintech impacted people's livelihoods and businesses during pandemic.

- The future of Fintech in emerging Asian country like India.

\section{Digital Technology in India and Evolution and adoption}

Digital technology in India has gained great momentum during last 10 years, because of increase in digital literacy among the people of every age and gender and with the increased usage of Internet and smartphones, it has fuelled the usage of digital applications. India was one of the early adopters in identifying the need of Financial technology to boost the economy and to attract the major Fintech players to set up the offices in India.

According to the research conducted by McKinsey (2019), India had 560 million Internet subscribers in 2018 (Pre-COVID-19) second only to China. And stands second in the app downloads. The low cost smartphones and economical internet price has helped people to perform more activities on the internet than ever before. The below data from Priori Data, Strategy Analytics shows the Indian digital adoption rankings. From the data we can observe that the increase in enrolment on various digital identity programs like Aadhar and Digi locker(to save digital secure versions of certificates, licence, documents) etc.

India is standing no 2 in app downloads in 2018 with 12.3 billion downloads. This specifies the adoption of app based products in the people mindsets has increased. 


\section{India is among the top two countries globally on many key dimensions of digital adoption.}

India No. 1 globally

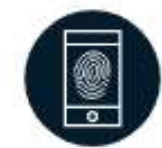

1.2 billion people enrolled in the world's largest uniquedigital-identity program

India No. 2 globally, behind China

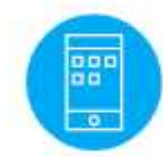

12.3 billion

app downloads in 2018

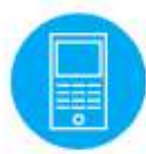

1.17 billion wireless-phone subscribers

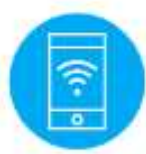

560 million

internet

subscribers

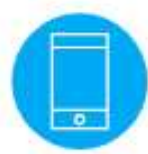

354 million smartphone devices

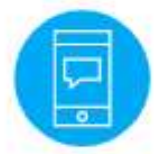

294 million users engaged in social media

Source: Priori Data; Strategy Analytics; Telecom Regulatory Authority of India; Unique Identification Authority of India; We Are Social; McKinsey Global Institute analysis

The introduction of UPI (Unified Payment Interface) from Government of India before COVID-19 started, helped many people to accustom to the digital payments transactions and also for the businesses to maintain UPI QR scans to receive payments.

Demonetization, When Government announced ban on Rs 500 and Rs 1000 few years back, people and businesses have adopted quickly to digital payments. The growth of Indian grown Fintech companies like PayTM, PhonePe and giant MNCs like Google Pay helped people to quickly adopt to the UPI (Unified Payment Interface) Payments quickly. UPI allows the consumers to pay securely through any of the registered APP which has securely linked to the ones bank account. Below figure shows the UPI usage across India in Financial Year 2019, by platform (Statista 2019)

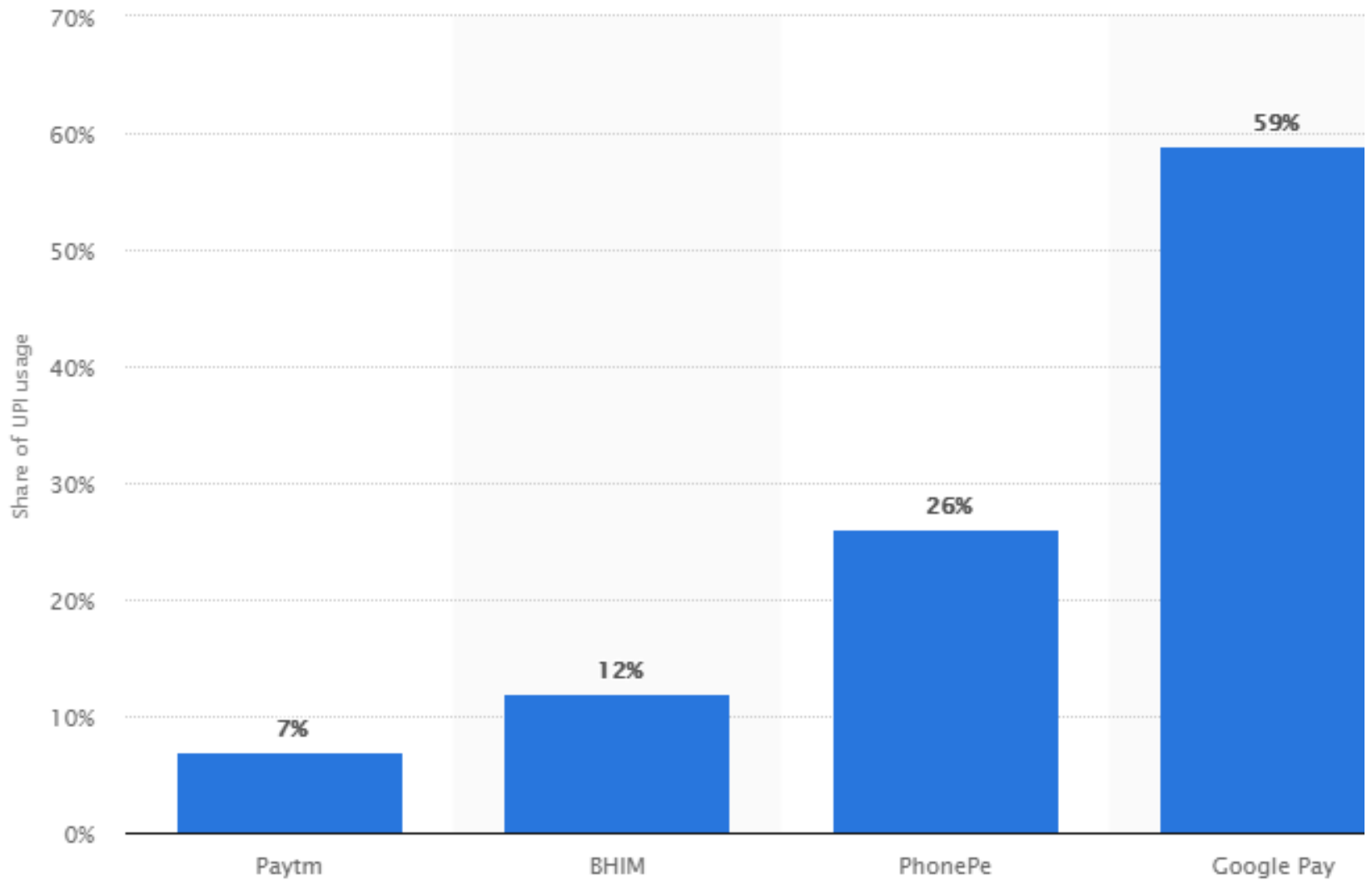

(Source Statista 2021)

The Google Pay has the highest share in the UPI Market and with Indian grown start up PhonePe with $28 \%$ share. 
The UPI transactions has increased tremendously during the past 1 year with more than 2000 Mn* in volume (During COVID-19). The recent reports from NPCI (National Payment Corporation of India) data shows the transactions.

The below statistics from NPCI, shows the data* of the transactions and the value through Fintech's (Digital Payments)

* This data excludes the transactions having debit/credit to the same account for the month of August 2018 onwards

\begin{tabular}{|c|c|c|c|}
\hline Month & No. of Banks live on UPI & Volume (in Mn) & Value (in Cr.) \\
\hline Feb-21 & 213 & $2,292.90$ & $4,25,062.76$ \\
\hline Jan-21 & 207 & 2302.73 & $4,31,181.89$ \\
\hline Dec-20 & 207 & $2,234.16$ & $4,16,176.21$ \\
\hline Nov-20 & 200 & $2,210.23$ & $3,90,999.15$ \\
\hline Oct-20 & 189 & $2,071.62$ & $3,86,106.74$ \\
\hline Sept-20 & 174 & $1,800.14$ & $3,29,027.66$ \\
\hline Aug-20 & 168 & 1618.83 & $2,98,307.61$ \\
\hline
\end{tabular}

The increase in the volume, value and the number of banks participating in UPI has increased drastically when compared to the below statistics. For example, in October 2019, only 141 banks were live with UPI and the volume of transactions were very negligible considering the size of the population India has.

\begin{tabular}{|c|c|c|c|}
\hline Month & No. of Banks live on UPI & Volume (in Mn) & Value (in Cr.) \\
\hline Jan-20 & 144 & $1,305.02$ & $216,242.97$ \\
\hline Dec-19 & 143 & $1,308.40$ & $202,520.76$ \\
\hline Nov-19 & 143 & $1,218.77$ & $189,229.09$ \\
\hline Oct-19 & 141 & $1,148.36$ & $191,359.94$ \\
\hline
\end{tabular}

India Payments Bank evolution which has changed the traditional approach of the banking system

The government was also responsible for introducing Payments banks to reach the unbanked public and to compete with the Public and private banks to give best services to the customers. These Payments banks work as a Digital or Hybrid model (Digital and brick and motor) banks which provides majority of the basic services provided by the banks in India. For example, Post Office which has more than 1.5 lacs centres in India has become Payments Bank. This not only allowed to reach millions of people in rural areas, semi-rural areas, but also helped many unbanked people to open a basic bank account through which they were able to make financial transactions.

The Payment banks not only helped unbanked but also opened doors to small businesses in Rural India, who have had difficulties in opening or maintaining the bank accounts in major banks due to various reasons like lack of availability of branches in rural places or cost to maintain the bank accounts. The Payments Bank of Post office (Which has digital and branch presence - inside post office) which has opened in 2018 had acquired record more than 4.0 crore customers by December 2020.

In contrast, Digital Payment Banks like PayTM Payment Bank has increased it's during the COVID-19 year, which saw the profits Rs 29.8 Crores PAT for FY 2020, up from Rs.19.2 Crore FY 2019. It has been largely led by higher customer acquisition in smaller cities \& towns to drive financial inclusion in the country. 


\title{
Say Hello to Revolutionary Banking!
}

\author{
- Paperless account opening \\ - No minimum balance requirement \\ - Free unlimited money transfers \\ and much more
}

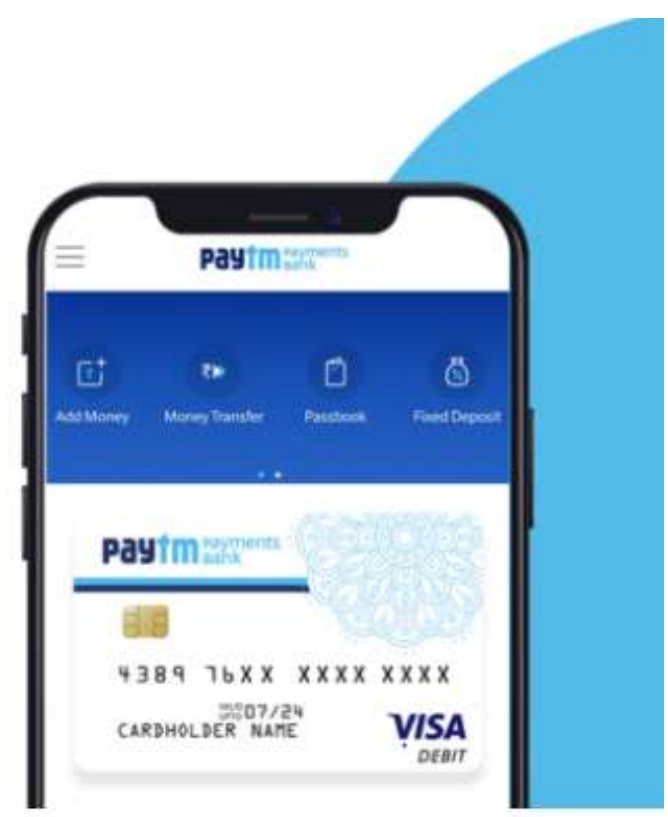

Source: PayTM 2020

Image depicting the home screen of PayTM Payments Bank, which boasts for having paperless account opening process, with no minimum balance requirement to maintain with free unlimited money transfers to other bank accounts. And also providing the Visa Debit virtual debit card to perform any ecommerce transactions etc.

\section{Role of QR Codes \\ QR Codes - The New Age Tech Shaping India’s Digital Payments Landscape}

Nobody in India could have predicted the success of the Quick Response Code, or QR code, which is in the process of making payments easier a decade ago. QR codes, which were invented in Japan in the mid-1990s, can hold up to 4,296 alphanumeric characters and, unlike barcodes, can be scanned in any direction to facilitate payment. merchant is not required to install a point-ofsale system in their establishment. This lowers the barrier to low-cost merchant acquisition. Aside from that, modern-day customers are becoming increasingly impatient, and they want a solution that is immediately available in their hands, which QR codes provide. QR eliminates the need for some transaction-related data to be entered, which appeals to today's youth and decreases transactionrelated errors.

QR is also slowly but steadily improving the way the country pays its bills. Consider getting your light bill in the mail and seeing a QR code on the envelope.

QR code adoptions for small and medium businesses in Rural and semi-rural India has increased post demonetization. The cities and towns were the early adopters, but the increase in usage of QR codes was only became possible because of its availability and easy to use feature. As customers do not require to enter any details to send the payments to the vendor, the simple scan and pay feature helped many people to adopt to the contact less payments very quickly.

\section{COVID-19 19 Opportunity in crisis for Fintech?}

- This had led to many new start-ups' in Fintech space which are contributing to the development of the economy

- $\quad$ Fintech firms are becoming more customer centric with innovative approaches to help individuals to manage their finances well.

- $\quad$ Pandemic has led to surge of digital payments for day to day activities of the people's life.

- Many Ecommerce companies are opened up digital payment platform to lure and take advantage of their customer base.

Example: Amazon which has started as the ecommerce company in the US, invested heavily in India. The business model also helped them to partner with the local vendors and suppliers and make them business sellers in the Ecommerce space. Amazon was one of the few firms which has quickly adopted to the consumer behaviour of the customers and vendors. With the large customer base, it has acquired over the years, it has started the UPI payments through its "Amazon Pay" which not only renders payments services to its customers, but also gives rewards, points and cashbacks on selected transactions. This has led people to bend towards UPI payments as it is easy, secure and faster service than traditional bank transfers.

Digital payments have been the flag bearer of the Indian FinTech space. In 2010, India launched its first real-time payments systems 'IMPS' and introduced UPI in 2016. There are 375 Payment start-up's in the country. Mobile/digital wallets, gateways, POS/ mobile 
POS sub-segments account for over $50 \%$ of the payment start-up's in India. In 2020, online transactions grew by $80 \%$ in India as compared to 2019 .

India will contribute $\mathbf{2 . 2 \%}$ to the world's digital payments market by $\mathbf{2 0 2 3}$, and the value of such transactions is expected to reach $\$ 12.4$ TN globally by 2025 .

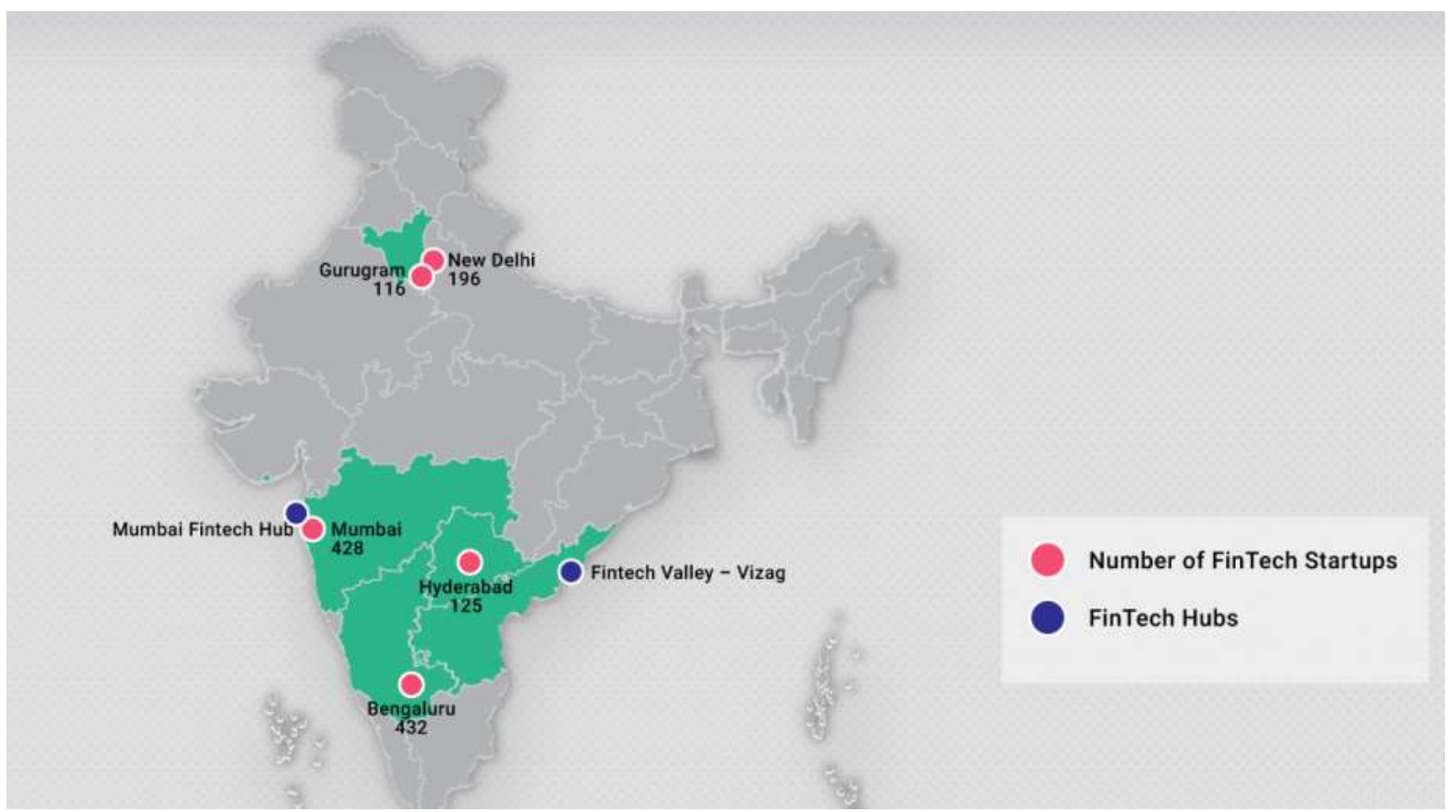

Source Invest India 2020

\section{Adverse Effects of COVID-19 on SMEs}

The COVID-19 pandemic's negative effects are affecting major sectors of the Indian economy, with automotive, retail, aviation, and hospitality bearing the brunt of the shutdown. As a result, fast-growing digital payments, which are closely related to the aforementioned industries, have suffered. Shuttered stores, travel bans, and lower discretionary consumer spending (on eating out, movies, and entertainment, for example) are all hurting digital payments.

Airlines, tourism, hospitality, hotels, entertainment, e-commerce (non-essentials), and restaurants, among other industries, have seen declines in digital payment volume. Furthermore, due to the temporary closure of borders, cross-border payments, whether $\mathrm{B} 2 \mathrm{~B}$ or $\mathrm{C} 2 \mathrm{~B}$, have dramatically decreased, resulting in restricted goods movement. International remittances have also been impacted, and they have decreased.

However, some areas are seeing a rise in digital payments as a result of increased usage during the lockout. Online grocery stores, supermarkets, OTT players (telecom and media), EdTechs, online gaming, recharges, and utility/bill payments are just a few examples.

\begin{tabular}{|l|l|}
\hline $\begin{array}{l}\text { Negative Effects of COVID-19 on SMEs in below } \\
\text { Industries }\end{array}$ & Verticals Boomed during COVID-19 \\
\hline Airline & FinTech \\
\hline Travel & MarTech \\
\hline Restaurants & Ecommerce \\
\hline Auto and Engineering & Online delivery \\
\hline Construction & Local groceries stores, essential \\
\hline Entertainment industry like cinemas & OTT, streaming platforms, Digital consultations, etc \\
\hline
\end{tabular}

Future Prediction of Fintech on Emerging markets and its impact on livelihoods of people and for SMEs post COVID-19

- The digital currency exchange will increase tremendously, with many people adopting to use of digital wallet payments in local shops instead of using POS or cards directly.

- $\quad$ Personalized Financial APPs demand will increase in the future as customer's lifestyle changes and in the era of AI and ML this type of customer centric and customer specific personalisation's will help community to be financially secure. 
- $\quad$ Customer experience in the APPs especially digital banking APPs and Digital payments APPs will become paramount important to the banks and payments institution.

- Digital Receipts and paper less documentation will be a new norm in the future. Right from small retail markets to restaurants, MNCs to banks all will adopt to paper less digitally secured paperwork.

- $\quad$ As the use of smartphones will increase in emerging markets and the network technologies like 5G, 6G and secured WIFI service increases, there will be a demand for the Fintech companies who will deal with Opening Banking. By giving recommendation to the customers based on their spending, savings, goals, etc.

- Continued digital payments push: Governments, regulators, and banks will all continue to press for the adoption of digital payments. As digital means gain prominence and acceptance, they will move from a convenience to a need, there will be a significant shift away from cash.

- Catalyst for innovation: FinTechs will be at the forefront of the current crisis, which will serve as a catalyst for innovation. In comparison to PoS, there will be more e-commerce-based deals. All payment players will be required to rapidly develop Omni channel capabilities, which will connect payments in any environment, physical or digital.

- QR/link-based payments: QR code payments will see an uptick - as they are cost-effective and contactless. Offline to online payment options will also become more accessible. This will gain momentum because they will help many small and individual business owners (such as milk and vegetable vendors) earn payments while people are reluctant to use cash, ultimately leading to a decrease in cash usage.

- Increased online presence: Companies with a strong online presence are likely to suffer less as a result of the anticipated slowdown. Small businesses and players with little to no online presence can need to consider partnering with payment specialists. Banks and other payment service providers can give such businesses discounted rates to get them online.

\section{Future Trends}

- Contactless payments (e.g. QR), SMS link-based payments and wearables will see an uptick as the increase in demand for Smart phones, Smart watches, smart eyewear, secured SMS will be unfolded in the future to reach millions of people around the world.

- Increased consumer education programmes and anti-fraud measures

- Increase in virtual card issuance and usage

- Increased online presence of small and medium businesses

- Online, paperless processes for issuing items such as unsecured loans and credit cards without having to deal with someone in person

- $\quad$ Market behaviour shift - increased acceptance of digital payments

\section{Conclusion}

As the technology is changing rapidly, the demand for personalised applications especially from Fintech industry will increase for both consumers and Businesses. The COVID-19 Pandemic, not only made many industries, people and businesses to move towards digital payments and digital technologies, it also gave the industries an opportunity to move towards more digitalized society.

\section{References}

[1] Arnott L. (2016). An ecological exploration of young children's digital play: Framing children's social experiences with technologies in early childhood. Early Years, 36 (3), 1-18

[2] Bedford R., De Urabain I. R. S., Cheung C. H. M., Karmiloff-Smith A., Smith T. J. (2016). Toddlers' fine motor milestone achievement is associated with early touchscreen scrolling. Frontiers in Psychology, 7, 1108.

DOI: $10.3389 /$ fpsyg. 2016.01108

[3] Beschorner B., Hutchison A. (2013). iPads as a literacy teaching tool in early childhood. International Journal of Education in Mathematics, Science and Technology, 1 (1), 16-24

[4] Bird J., Edwards S. (2015). Children learning to use technologies through play: A digital play framework. British Journal of Educational Technology, 46 (6), 1149-1160

[5] Chaudron S. (2015). Young children (0-8) and digital technology: A qualitative exploratory study across seven countries. Retrieved from http://publications.jrc.ec.europa.eu/repository/handle/JRC93239

[6] Ching-Ting H., Ming-Chaun L., Chin-Chung T. (2014). The influence of young children's use of technology on their learning: A review. Journal of Educational Technology \& Society, 17 (4), 85-99

[7] Christakis D. A., Garrison M. M., Herrenkohl T., Haggerty K., Rivara F. P., Zhou C., Liekweg K. (2013). Modifying media content for preschool children: A randomized controlled trial. Pediatrics, 131 (3), 431-438

[8] Common Sense Media (2017). The Common Sense Census: Media use by kids age zero to eight. Retrieved from https://www.commonsensemedia.org/sites/default/files/uploads/research/csm_zerotoeight_fullreport_release_2.pdf

[9] Danby S., Davidson C., Ekberg S., Breathnach H., Thorpe K. (2016). "Let's see if you can see me": Making connections with Google Earth ${ }^{\mathrm{TM}}$ in a preschool classroom. Children's Geographies, 14 (2), 141-157 
[10] Davidson C., Given L. M., Danby S., Thorpe K. (2014). Talk about a YouTube video in preschool: The mutual production of shared understanding for learning with digital technology. Australasian Journal of Early Childhood, 39 (3), 76-83

[11] Puppala Venkat Kamesh. "Digital Technology-The 4th Industrial Revolution \& Beyond"

[12] Bakos J. Y. (1998). The emerging role of electronic marketplaces on the Internet. Communications of the ACM, 41 (8), 3542

[13] Baron J. P., Shaw M. J., Bailey A. D. (2000). Web-based e-catolog systems in B2B procurement. Communications of the ACM, 43 (5), 93-100 